\title{
Assessment of Longitudinal Measurement Invariance of Short Versions of the CES-D in Maternal Caregivers
}

\author{
Luis Villalobos-Gallegos ${ }^{1}$, Aldebarán Toledo-Fernández ${ }^{2}$ \\ ${ }^{1}$ Facultad de Medicina y Psicología. Universidad Autónoma de Baja California-Tijuana. \\ ${ }^{2}$ Universidad Anáhuac \\ *Corresponding author: Aldebarán Toledo-Fernández, PhD. E-mail address: aldebarantoledo@gmail.com
}




\section{Introduction}

In the study of emotional development, the family is a nodal factor to understand complex processes (e. g. emotional regulation). The emotional development of the child is closely related to several factors within a family system, such as the observation of significant others, parenting practices and emotional climate (Morris, Silk, Steinberg, Myers, \& Robinson, 2007). These determinants, in turn, are closely associated with the mental health status of the parents, particularly depressive symptoms in the maternal caregiver (biological mother or a substitutive figure), which play a decisive role in the child's optimal emotional development (Wu et al., 2018).

A large body of evidence has linked maternal caregiver depression to several negative processes, such as blunted neural activity (Meyer, Bress, Hajcak, \& Gibb, 2018), less use of secondary control coping (Reising et al., 2018), and a lower parent-adolescent relationship quality (Withers, Cooper, Rayburn, \& McWey, 2016), which are associated with depressive symptoms during adolescence. Studies analyzing trajectories of maternal caregiver depression, have found that a longitudinal pattern of chronicity increases the probability of offspring's psychopathology, when compared to less chronical trajectories (e. g. minimal and moderate depression) (Matijasevich et al., 2015).

One of the most common methods to assess depressive symptoms is the use of self-report scales. This method conveys several benefits: it requires minimal training, low administration time, and can be easily transported to clinical practice. However, amongst its most important caveats is that the metric of the score need equivalence in the factor structure between subgroups of the studied population. This is known as measurement invariance (MI) (Meredith \& Teresi, 2006). When MI is met, we can validly trust that between-group differences are not the result of measurement artifacts (Putnick \& Bornstein, 2016). An example of this is when the factor structure is invariant across gender, difference in the variable is the result of the presence of the latent trait, 
instead of a consequence of the lack of equivalence in loadings or other any other parameter of the factor model.

A second case of invariance is found in research involving repeated measures. It is assumed that a measurement has to maintain the same structure within a population, even when the latent scores change across time, this is known as longitudinal invariance (LI) (Widaman, Ferrer, \& Conger, 2010). In the context of latent variable modelling, LI has a major relevance in two scenarios (however is not limited to them): (1) when we test the efficacy of an intervention, the lack of LI increases the probability of bias in the assessment of the outcomes, and we become unable to ascertain whether positive or negative changes are related to the treatment or as the result of a measurement artifact; (2) in developmental research, we expect that the structure of the measurement remain constant, so the changes in the response to items are related to changes in the latent score.

The Center for Epidemiological Studies-Depression Scale (CES-D) (Radloff, 1977), is one of the most widely used scales to measure depression. There are some previous studies testing LI in the CES-D in adolescents and adults (Contrada, Boulifard, Idler, Krause, \& Labouvie, 2006; Ferro \& Speechley, 2013; Motl, Dishman, Birnbaum, \& Lytle, 2005; Verhoeven, Sawyer, \& Spence, 2013). In these studies, it is suggested that a one-first order/four-second order factor structure remains equivalent across time in versions ranging from 18-20 items.

A major limitation of these studies is that the results were interpreted as if the CES-D response options were numerical. The results of Monte Carlo studies for testing LI when responses are ordered categorical (such as the CES-D response options) recommend against the use of difference in fit indices (Liu et al., 2017; Sass, Schmitt, \& Marsh, 2014), which is a precise indicator when responses are, at least, approximately numerical, and also suggest to rely mostly in the use of Chi squared $\left(\chi^{2}\right) \mathrm{T}_{3}$ statistic (Holmes Finch \& French, 2019). 
A second practical issue regards to the development of CES-D short versions. Short forms maximize the use of the resources and the advantages of self-report scales. However, short versions require to be tested to determine whether they retain the longer versions' properties. To our knowledge, there are no studies testing LI in any of the short versions of the CES-D, and most of them focus only in MI (González et al., 2017).

Considering the value of a measurement tool for depression symptoms in maternal caregivers that is both brief and stable across time, we aimed to test LI for the short versions of the CES-D in this population. For this purpose, the analytic procedures follow the recommendations for ordered categorical responses (Liu et al., 2017).

\section{Method}

\section{Participants}

Data for this study was drawn from the Longitudinal Studies in Child Abuse and Neglect (LONGSCAN) consortium. In brief, LONGSCAN included maltreated or at-risk for maltreatment young children that were recruited in five sites (Baltimore, Chicago, Seattle, San Diego and North Carolina). It has a longitudinal design, which start measuring the participants at 4 years of age or younger (depending of the site) and made subsequent measures trough childhood, adolescence and the beginning of young adulthood. Yearly contacts with the participants were performed at each site, and extensive evaluations were conducted at ages 4, 6, 8, 12, 16, and 18 of the participants (for more information about measures, procedures and participants characteristics please see Runyan et al., 1998).

At several points of the study (mostly in early stages), data was provided from other informants besides the children. Particularly, maternal caregivers took CES-D when children were 4, 6, 12, 14 and 16 years (characteristics of maternal caregivers are displayed in Table 1). 


\section{Measure}

CES-D is a scale that has been widely used to test depression severity across several samples (Vilagut, Forero, Barbaglia, \& Alonso, 2016). It contains 20 items that were taken from previously validated depression scales to reflect depressed mood, guilt/worthlessness, helplessness/hopelessness, psychomotor retardation, loss of appetite, and sleep disturbance (Radloff, 1977). CES-D measures depression during the past week, with four response options: Rarely or none of the time (Less than 1 Day); Some or a little of the time (1-2 Days); Occasionally or a moderate amount of time (3-4 Days); Most or all of the time (5-7 days).

Several short versions ranging from 5 to 11 items were previously developed using different extraction methods such a factor analysis, discriminant function or Rasch measurement modeling (Andresen, Malmgren, Carter, \& Patrick, 1994; Cole, Rabin, Smith, \& Kaufman, 2004; Kohout, Berkman, Evans, \& Cornoni-Huntley, 1993; Santor \& Coyne, 1997; Shrout \& Yager, 1989). A summary of the short versions analyzed in this study is included in Table 2

\section{Statistical Analysis}

Descriptive data for each wave is displayed, using mean and standard deviation for numerical variables and frequency and percentage for categorical variables. For informative purposes one-way ANOVA (numerical variables) and chi square test (categorical variables) were conducted to test between-wave differences. When omnibus test obtained a $p<.05$, pairwise comparisons were conducted: Tuckey post-hoc test was performed for numerical data, and pairwise chi square test with Bonferroni $p$ value correction. For pairwise comparisons, significance was set at $p<.05$. 
The analysis of the invariance was conducted using the software Mplus 8 (Muthén \& Muthén, 2017). CES-D items were analyzed as ordered categorical indicators. Therefore, analysis was conducted using mean and variance adjusted weighted least squares (WLSMV) estimator. Procedures were followed as recommended by Liu et al. (2017). In brief, this paper suggests that the first step is to fit a baseline model which imposes no constrains but adds covariance terms between time-dependent factors and error terms. Subsequently equality constrains were imposed in loadings, thresholds and unique variances, in order to test the invariance in such levels. In this procedure, an indicator must be selected as a marker. A marker is an observable variable that is assumed that remains invariant across all measures. To assume invariance at a certain level the $\mathrm{p}$ value of the $\chi^{2}$ difference test must be $>.05$ (because of the use of WLSMV, this analysis was performed with the DIFFTEST option) when compared to the previous step.

When criteria for invariance is not met at the threshold or unique variance levels, performing a sensitivity analysis is needed to test the magnitude of the violation of the invariance. The procedure involves comparing the expected response probabilities between the corresponding non-invariant model and its previous step (for more information please see Liu et al., 2017). If necessary, this procedure is computed using R software ver. 3.6.1 (R Core Team, 2018).

\section{Results}

\section{Participant characteristics}

Participants age at the first wave was about 32 years, and as expected it increased with the subsequent waves. Marital status, which was predominantly single or married, also change with time, as higher proportion of participants declared to be married and the percentage of single participants decreased (The rest of categories of marital status remain relatively unchanged). The changes in employment, income and education in the participants shown a similar patter, as the 
waves progresses higher levels of educations, full time employment and higher income increased (Table 2)

\section{LI analysis}

Every model achieved optimal goodness of fit (RMSEA <.05, CFI > .95) in most of the steps of the analysis (with exception of the B-version in the unique factor). However, only A, E and F displayed loading invariance, with non-significant results in chi square difference test, indicating that there is little change of the loadings across the waves for these versions. When threshold and unique factor invariance were tested, no model met with the criteria of non-significance in chi square difference test, therefore, there is little evidence of invariance were a more astringent approach is used (Table 3).

\section{Sensitivity analysis}

Considering that chi square difference test is prone to type I error sensitivity analysis was conducted in the versions that endorsed loading invariance (A, E and F). Using a criterion of a difference in the expected response probability <.05 it was found that: 1) Violations in invariance differ in each of the versions, for instance, in version A mostly of the responses for item 14 surpassed the expected difference, but, in version F, mostly of the problems were found in 16-year wave and in the 4-years wave in the version E; 2) A few items, such as, item 14, was problematic across all waves, particularly in version A; the same problem was found in item 8 in the versions $\mathrm{E}$ and $\mathrm{F}$, however, the expected difference was not as large and common, and mostly appear in the higher response options (3 and 4); 3) In version A, in the 4-year wave, the lowest response option (0) had a high difference for most of the items (Tables 4-6). 


\section{Discussion}

This study sought to test the LI of the short versions of the CES-D in a sample of maternal caregivers. We found that three of the analyzed versions had enough evidence for loading invariance, which is the weakest form of invariance (Meredith \& Teresi, 2006), however, none of the short versions were unable to meet the statistical criteria for subsequent and more astringent levels of invariance (threshold and unique variance).

Consequences of non-invariance are not only restricted to the interpretation of the data when subsequent measures are taken. As show by a previous Monte Carlo study (Liu \& West, 2018), the lack of FI in a measure might result in non-trivial bias when we use the measures for latent growth modeling. Even in the version that achieved loading invariance only (A, E and F), if we decided to use any of them for a longitudinal analysis (e. g. latent growth model), there could be somewhat large influence in every parameter (e. g. Mean/variance linear slope, Intercept variance, and intercept/slope covariance), resulting in a highly unprecise estimation.

The previous studies using longer versions of the CES-D, suggest that the measure displays LI, based mostly in the change of fir indexes (Ferro \& Speechley, 2013; Motl et al., 2005; Verhoeven et al., 2013). If we stick to these recommendations, most of the short versions that we analyzed could be considered as longitudinally invariant. However, as stated before, it was found that the behavior of the fit indexes in categorical responses is non-equivalent (Liu et al., 2017). Therefore, the assessment of LI for ordered-categorical response variables must be based mostly in chi square difference test. In the case of the CES-D, treating the responses as numerical to avoid this problem is not an option, because the number of response options (four) leads to bias when estimators for numerical variables are used (e. g. ML, MLMV or MLR). So, as stated in the literature the best estimator for this purpose is WLSMV (Also known as diagonally weighted least squares)(Li, 2016). 
There are three basic sources that may explain why CES-D was non-invariant: the population, the time elapsed between waves, and the measure itself. It is expected that constructs as depression, would be stable over time in adults, such as the maternal caregivers, however currently there is little evidence if the latent structure of depression remains constant during adulthood. As we know, there are complex affective changes related to the transition from being the mother of an infant, to becoming the mother of an adolescent (Van der Giessen et al., 2014).

In our study, several years elapsed between measures (eight years between second and third wave). This could affect in several ways the estimation of FI. The first and most obvious, which also could be considered as a limitation of our study, is the attrition of participants. It is known that this is one of the most problematic issues in longitudinal research, that increases with the time, and it possible that the sample for each wave would change enough to alter the results. Another important issue is related to the evolution of the structure of depression. It seems possible that the covariance between depression indicators remains stable only during a relatively short period of time (e. g. six months, one year), however, the smallest time-window in our study was two years. This leaves a high chance for depression structure to "evolve" with time, therefore, the item covariance in the CES-D would also change, leading to a non-invariant structure.

The third possible source of non-invariance, the CES-D itself. Is important to note that the CES-D was developed about 50 years ago (Radloff, 1977) using items for previous questionnaires. This suggest that the concept of depressive syndrome in which the CES-D is based, may not be as refined as the one included in the most current classifications, such as, DSM-5 of ICD-11. Another plausible explanation, directly associated with the measures is the four-point response format, that is based in the count of days endorsing the symptoms. Is important to understand that the cognitive process underlying the response to a scale requires interpretation of the stimuli (the item), assessment of the subjective state, and selection of the response option based on the previous 
process. In the case of depressive symptoms, frequency (count of days above a perceived depression threshold) and severity (overall intensity of the depressive symptom) are two different dimensions. In the case of CES-D, responses only capture frequency, therefore, it is possible that the overall appraisal of the each symptom would be stable in time (loading invariance), however specific responses (threshold and unique invariance) lack of such stability, as a result of only considering frequency, leaving out intensity. A plausible option to improve CES-D, would be to increase the response options to additionally asses the severity, however, a further study in this regard is required. A last insight regarding to the non-invariance from the CES-D comes from the studies using a network analysis approach. Contrary to latent variable modeling, depression is not assumed to be an unobservable variable that explains the change of a set of indicators, but the result of the interrelations of such indicators (depressive symptoms) (Borsboom \& Cramer, 2013). In a previous study based in this approach depression symptoms in maternal caregivers was measured using the CES-D. When the stability of the network (an analogous version of LI in network approach) was analyzed, the results seemed inconclusive as the adjacency analysis show moderate correlations, but the network structure did not remain invariant across waves (Santos, Kossakowski, Schwartz, Beeber, \& Fried, 2018). This data suggested that the CES-D structure fails to prove equivalence across time, and that limitation is clear regardless of the analytic approach.

We believe that our study raises awareness of the use of any of the brief versions of the CES-D in longitudinal research. If we add our results to the previous evidence testing other depression measures (Fried et al., 2016) it would seem that testing LI in widely used depression measures is a mandatory subject for development and treatment researchers, to prevent misleading and biased conclusions. Also, assessment of LI, would be a required practice, to determine whether the classical assumption about the stability of depression structure across time in adults can be 
sustained or it changes as the result of environmental variables (e. g. treatment changes the structure of the correlations between symptoms, as suggested by Blanken et al. [2019]). 


\section{References}

Andresen, E. M., Malmgren, J. A., Carter, W. B., \& Patrick, D. L. (1994). Screening for depression in well older adults: Evaluation of a short form of the CES-D. American Journal of Preventive Medicine, 10, 77-84. doi:10.1016/s0749-3797(18)30622-6

Blanken, T. F., Van Der Zweerde, T., Van Straten, A., Van Someren, E. J. W., Borsboom, D., \& Lancee, J. (2019). Introducing Network Intervention Analysis to Investigate Sequential, Symptom-Specific Treatment Effects: A Demonstration in Co-Occurring Insomnia and Depression. Psychotherapy and Psychosomatics. doi:10.1159/000495045

Borsboom, D., \& Cramer, A. O. J. (2013). Network Analysis: An Integrative Approach to the Structure of Psychopathology. Annual Review of Clinical Psychology. doi:10.1146/annurevclinpsy-050212-185608

Cole, J. C., Rabin, A. S., Smith, T. L., \& Kaufman, A. S. (2004). Development and validation of a Rasch-derived CES-D short form. Psychological Assessment, 16, 360-372. doi:10.1037/1040-3590.16.4.360

Contrada, R. J., Boulifard, D. A., Idler, E. L., Krause, T. J., \& Labouvie, E. W. (2006). Course of depressive symptoms in patients undergoing heart surgery: Confirmatory analysis of the factor pattern and latent mean structure of the Center for Epidemiologic Studies Depression Scale. Psychosomatic Medicine. doi:10.1097/01.psy.0000244391.56598.10

Ferro, M. A., \& Speechley, K. N. (2013). Factor structure and longitudinal invariance of the Center for Epidemiological Studies Depression Scale (CES-D) in adult women: Application in a population-based sample of mothers of children with epilepsy. Archives of Women's Mental Health. doi:10.1007/s00737-013-0331-5

Fried, E. I., van Borkulo, C. D., Epskamp, S., Schoevers, R. A., Tuerlinckx, F., \& Borsboom, D. (2016). Measuring depression over time . . . Or not? Lack of unidimensionality and 
longitudinal measurement invariance in four common rating scales of depression. Psychological Assessment, 28, 1354-1367. doi:10.1037/pas0000275

González, P., Nuñez, A., Merz, E., Brintz, C., Weitzman, O., Navas, E. L., ... Gallo, L. C. (2017). Measurement properties of the Center for Epidemiologic Studies Depression Scale (CES-D 10): Findings from HCHS/SOL. Psychological Assessment, 29, 372-381. doi:10.1037/pas0000330

Holmes Finch, W., \& French, B. F. (2019). Equivalence Testing for Factor Invariance Assessment with Categorical Indicators. In M. Wiberg, S. Culpepper, R. Janssen, J. González, \& D. Molenaar (Eds.), Quantitative Psychology 83rd Annual Meeting of the Psychometric Society, New York, NY 2018 (pp. 229-242). Cham, Switzerland: Springer Nature. doi:10.1007/978-3030-01310-3_21

Kohout, F. J., Berkman, L. F., Evans, D. A., \& Cornoni-Huntley, J. (1993). Two Shorter Forms of the CES-D Depression Symptoms Index. Journal of Aging and Health, 5, 179-193. doi:10.1177/089826439300500202

Li, C. H. (2016). Confirmatory factor analysis with ordinal data: Comparing robust maximum likelihood and diagonally weighted least squares. Behavior Research Methods. doi:10.3758/s13428-015-0619-7

Liu, Y., Millsap, R. E., West, S. G., Tein, J. Y., Tanaka, R., \& Grimm, K. J. (2017). Testing measurement invariance in longitudinal data with ordered-categorical measures. Psychological Methods. doi:10.1037/met0000075

Liu, Y., \& West, S. G. (2018). Longitudinal Measurement Non-Invariance with OrderedCategorical Indicators: How are the Parameters in Second-Order Latent Linear Growth Models Affected? Structural Equation Modeling, 25, 762-777. doi:10.1080/10705511.2017.1419353 
Matijasevich, A., Murray, J., Cooper, P. J., Anselmi, L., Barros, A. J. D., Barros, F. C., \& Santos, I. S. (2015). Trajectories of maternal depression and offspring psychopathology at 6 years: 2004 Pelotas cohort study. Journal of Affective Disorders. doi:10.1016/j.jad.2014.12.012

Meredith, W., \& Teresi, J. A. (2006). An essay on measurement and factorial invariance. Medical Care. doi:10.1097/01.mlr.0000245438.73837.89

Meyer, A., Bress, J. N., Hajcak, G., \& Gibb, B. E. (2018). Maternal Depression Is Related to Reduced Error-Related Brain Activity in Child and Adolescent Offspring. Journal of Clinical Child and Adolescent Psychology. doi:10.1080/15374416.2016.1138405

Morris, A. S., Silk, J. S., Steinberg, L., Myers, S. S., \& Robinson, L. R. (2007). The role of the family context in the development of emotion regulation. Social Development. doi:10.1111/j.1467-9507.2007.00389.x

Motl, R. W., Dishman, R. K., Birnbaum, A. S., \& Lytle, L. A. (2005). Longitudinal invariance of the center for epidemiologic studies-depression scale among girls and boys in middle school. Educational and Psychological Measurement. doi:10.1177/0013164404266256

Muthén, L. K., \& Muthén, B. O. (2017). Mplus user’s guide (8th ed.). Muthén \& Muthén.

Putnick, D. L., \& Bornstein, M. H. (2016). Measurement Invariance Conventions and Reporting: The State of the Art and Future Directions for Psychological Research. Developmental Review. doi:10.1016/j.dr.2016.06.004.Measurement

R Core Team. (2018). R: A Language and Environment for Statistical Computing. Vienna, Austria: R Foundation for Statistical Computing.

Radloff, L. S. (1977). The CES-D Scale: A Self-Report Depression Scale for Research in the General Population. Applied Psychological Measurement. doi:10.1177/014662167700100306

Reising, M. M., Bettis, A. H., Dunbar, J. P., Watson, K. H., Gruhn, M., Hoskinson, K. R., \& 
Compas, B. E. (2018). Stress, coping, executive function, and brain activation in adolescent offspring of depressed and nondepressed mothers. Child Neuropsychology. doi:10.1080/09297049.2017.1307950

Runyan, D. K., Curtis, P. A., Hunter, W. M., Black, M. M., Kotch, J. B., Bangdiwala, S., ... Landsverk, J. (1998). Longscan: A consortium for longitudinal studies of maltreatment and the life course of children. Aggression and Violent Behavior. doi:10.1016/S13591789(96)00027-4

Santor, D. A., \& Coyne, J. C. (1997). Shortening the CES-D to improve its ability to detect cases of depression. Psychological Assessment, 9, 233-243. doi:10.1037/1040-3590.9.3.233

Santos, H. P., Kossakowski, J. J., Schwartz, T. A., Beeber, L., \& Fried, E. I. (2018). Longitudinal network structure of depression symptoms and self-efficacy in low-income mothers. PLoS ONE, 13, 1-16. doi:10.1371/journal.pone.0191675

Sass, D. A., Schmitt, T. A., \& Marsh, H. W. (2014). Evaluating Model Fit With Ordered Categorical Data Within a Measurement Invariance Framework: A Comparison of Estimators. Structural Equation Modeling. doi:10.1080/10705511.2014.882658

Shrout, P. E., \& Yager, T. J. (1989). Reliability and validity of screening scales: Effect of reducing scale length. Journal of Clinical Epidemiology, 42, 69-78. doi:10.1016/0895-4356(89)900279

Van der Giessen, D., Hollenstein, T., Hale, W. W., Koot, H. M., Meeus, W., \& Branje, S. (2014). Emotional Variability in Mother-Adolescent Conflict Interactions and Internalizing Problems of Mothers and Adolescents: Dyadic and Individual Processes. Journal of Abnormal Child Psychology. doi:10.1007/s10802-014-9910-9

Verhoeven, M., Sawyer, M. G., \& Spence, S. H. (2013). The factorial invariance of the CES-D during adolescence: Are symptom profiles for depression stable across gender and time? 
Journal of Adolescence. doi:10.1016/j.adolescence.2012.10.007

Vilagut, G., Forero, C. G., Barbaglia, G., \& Alonso, J. (2016). Screening for depression in the general population with the center for epidemiologic studies depression (ces-d): A systematic review with meta-analysis. PLoS ONE. doi:10.1371/journal.pone.0155431

Widaman, K. F., Ferrer, E., \& Conger, R. D. (2010). Factorial invariance within longitudinal structural equation models: Measuring the same construct across time. Child Development Perspectives. doi:10.1111/j.1750-8606.2009.00110.x

Withers, M. C., Cooper, A., Rayburn, A. D., \& McWey, L. M. (2016). Parent-adolescent relationship quality as a link in adolescent and maternal depression. Children and Youth Services Review. doi:10.1016/j.childyouth.2016.09.035

Wu, V., East, P., Delker, E., Blanco, E., Caballero, G., Delva, J., ... Gahagan, S. (2018). Associations Among Mothers' Depression, Emotional and Learning-Material Support to Their Child, and Children's Cognitive Functioning: A 16-Year Longitudinal Study. Child Development. doi:10.1111/cdev.13071 
Table 1

Summary of the CES-D Brief versions analyzed in this study

\begin{tabular}{|c|c|c|c|c|c|c|c|c|}
\hline \multirow{2}{*}{ \# } & \multirow{2}{*}{ Item } & \multicolumn{7}{|c|}{ Version } \\
\hline & & A & B & $\mathrm{C}$ & $\mathrm{D}$ & $\mathrm{E}$ & $\mathrm{F}$ & $\mathrm{G}$ \\
\hline 1 & Bothered & 0 & 0 & 1 & 0 & 1 & 1 & 0 \\
\hline 2 & Appetite & 0 & 0 & 0 & 0 & 0 & 0 & 1 \\
\hline 3 & Blues & 0 & 0 & 1 & 0 & 0 & 1 & 0 \\
\hline 4 & As good & 0 & 0 & 0 & 0 & 0 & 1 & 0 \\
\hline 5 & Mind & 0 & 0 & 1 & 0 & 1 & 1 & 0 \\
\hline 6 & Depressed & 1 & 1 & 1 & 1 & 1 & 0 & 1 \\
\hline 7 & Effort & 0 & 0 & 1 & 1 & 1 & 1 & 1 \\
\hline 8 & Hopeful & 0 & 1 & 0 & 0 & 1 & 1 & 0 \\
\hline 9 & Failure & 0 & 0 & 0 & 0 & 0 & 1 & 0 \\
\hline 10 & Fearful & 0 & 0 & 0 & 0 & 1 & 1 & 0 \\
\hline 11 & Sleep & 1 & 0 & 1 & 1 & 1 & 0 & 1 \\
\hline 12 & Нарру & 0 & 1 & 1 & 1 & 1 & 0 & 1 \\
\hline 13 & Talked less & 0 & 0 & 0 & 0 & 0 & 0 & 0 \\
\hline 14 & Lonely & 1 & 0 & 0 & 1 & 1 & 1 & 1 \\
\hline 15 & Unfriendly & 0 & 0 & 0 & 1 & 0 & 1 & 1 \\
\hline 16 & Enjoyed & 0 & 0 & 1 & 1 & 0 & 0 & 1 \\
\hline 17 & Crying & 1 & 1 & 0 & 0 & 0 & 0 & 0 \\
\hline 18 & Felt sad & 0 & 0 & 1 & 1 & 0 & 0 & 1 \\
\hline 19 & Disliked & 0 & 1 & 0 & 1 & 0 & 0 & 1 \\
\hline 20 & Get Going & 1 & 0 & 0 & 1 & 1 & 0 & 1 \\
\hline \multicolumn{2}{|c|}{ Total items } & 5 & 5 & 9 & 10 & 10 & 10 & 11 \\
\hline
\end{tabular}

Notes: 0-Item is not in the version; 1-Item is in the version. Versions were developed by: (A/B) Shrout \& Yager, 1989; (C) Santor \& Coyne, 1997; (D/G) Kohout et al., 1993; (E) Andresen et al., 1994; and (F) Cole et al., 2004. 
Table 2

Respondents' characteristics by wave

\begin{tabular}{|c|c|c|c|c|c|c|}
\hline & $\begin{array}{l}\text { Wave } 4 \\
(n=1167)\end{array}$ & $\begin{array}{l}\text { Wave } 6 \\
(n=1123)\end{array}$ & $\begin{array}{l}\text { Wave } 12 \\
(n=945)\end{array}$ & $\begin{array}{l}\text { Wave } 14 \\
(n=930)\end{array}$ & $\begin{array}{l}\text { Wave } 16 \\
(n=865)\end{array}$ & \multirow{2}{*}{ Statistical difference } \\
\hline & $\begin{array}{l}\mathrm{M}(\mathrm{SD}) \text { or } \\
\text { Freq. } \%)\end{array}$ & $\begin{array}{l}\text { M(SD) or } \\
\text { Freq. }(\%)\end{array}$ & $\begin{array}{l}\mathrm{M}(\mathrm{SD}) \text { or } \\
\text { Freq. }(\%)\end{array}$ & $\begin{array}{l}\text { M(SD) or } \\
\text { Freq. }(\%)\end{array}$ & $\begin{array}{l}\text { M(SD) or } \\
\text { Freq. }(\%)\end{array}$ & \\
\hline Age & $32.8(10.3)^{\mathrm{a}}$ & $34.9(10.5)^{\mathrm{b}}$ & $40.9(10.4)^{\mathrm{c}}$ & $42.2(10.3)^{\mathrm{c}}$ & $44.4(10.6)^{\mathrm{d}}$ & $\mathrm{F}(4,5061)=229.3 * *$ \\
\hline Race & & & & & & $\chi^{2}(24)=23.14$ \\
\hline White & $391(33.5)^{\mathrm{a}}$ & $373(32.6)^{\mathrm{a}}$ & $307(32.3)^{\mathrm{a}}$ & $288(30.9)^{\mathrm{a}}$ & $278(31.8)^{\mathrm{a}}$ & \\
\hline Black & $609(20.7)^{\mathrm{a}}$ & $625(54.6)^{\mathrm{a}}$ & $529(55.6)^{\mathrm{a}}$ & $530(56.9)^{\mathrm{a}}$ & $478(54.8)^{\mathrm{a}}$ & \\
\hline Hispanic & $89(7.6)^{\mathrm{a}}$ & $86(7.5)^{\mathrm{a}}$ & $63(6.6)^{\mathrm{a}}$ & $62(6.7)^{\mathrm{a}}$ & $70(8.0)^{\mathrm{a}}$ & \\
\hline Native American & $16(1.4)^{\mathrm{a}}$ & $6(.5)^{\mathrm{a}}$ & $13(1.4)^{\mathrm{a}}$ & $16(1.7)^{\mathrm{a}}$ & $11(1.3)^{\mathrm{a}}$ & \\
\hline Asian & $9(.8)^{\mathrm{a}}$ & $4(.3)^{\mathrm{a}}$ & $3(.3)^{\mathrm{a}}$ & $2(.2)^{\mathrm{a}}$ & $4(.5)^{\mathrm{a}}$ & \\
\hline Mixed race & $36(3.1)^{\mathrm{a}}$ & $33(2.9)^{\mathrm{a}}$ & $24(2.5)^{\mathrm{a}}$ & $27(2.9)^{\mathrm{a}}$ & $19(2.2)^{\mathrm{a}}$ & \\
\hline Other & $18(1.5)^{\mathrm{a}}$ & $18(1.6)^{\mathrm{a}}$ & $12(1.3)^{\mathrm{a}}$ & $6(.6)^{\mathrm{a}}$ & $13(1.5)^{\mathrm{a}}$ & \\
\hline Marital status & & & & & & $\chi^{2}(16)=77.4^{* *}$ \\
\hline Married & $385(32.9)^{\mathrm{a}}$ & $382(33.3)^{\mathrm{a}}$ & $364(38.3)$ & $356(38.2)$ & $336(38.4)$ & \\
\hline Single & $526(45.0)^{\mathrm{a}}$ & $481(42.0)^{\mathrm{a}}$ & $327(34.4)^{\mathrm{b}}$ & $317(34.0)^{\mathrm{b}}$ & $283(32.3)^{b}$ & \\
\hline Separated & $88(7.5)^{\mathrm{a}}$ & $94(8.2)^{\mathrm{a}}$ & $77(8.1)^{\mathrm{a}}$ & $75(8.1)^{\mathrm{a}}$ & $65(7.4)^{\mathrm{a}}$ & \\
\hline Divorced & $151(12.9)^{\mathrm{a}}$ & $158(13.8)^{\mathrm{a}}$ & $143\left(15.0^{\mathrm{a}}\right.$ & $140(15.0)^{\mathrm{a}}$ & $142(16.2)^{\mathrm{a}}$ & \\
\hline Widowed & $19(1.6)^{\mathrm{a}}$ & $31(2.7)^{\mathrm{a}, \mathrm{b}}$ & $40(4.2)^{\mathrm{b}, \mathrm{c}}$ & $43(4.6)^{\mathrm{c}}$ & $49(5.6)^{\mathrm{c}}$ & \\
\hline High school & & & & & & $\chi^{2}(8)=250.4^{* *}$ \\
\hline No diploma & $389(44.8)^{\mathrm{a}}$ & $361(44.6)^{\mathrm{a}}$ & $237(24.9)^{\mathrm{b}}$ & $223(24.0)^{\mathrm{b}}$ & $203(23.3)^{b}$ & \\
\hline Diploma & $325(37.4)^{\mathrm{a}}$ & $304(37.5)^{\mathrm{a}}$ & $561(59.1)^{b}$ & $569(61.3)^{b}$ & $534(61.2)^{b}$ & \\
\hline Equivalence test & $154(17.7)^{\mathrm{a}}$ & $145(17.9)^{\mathrm{a}}$ & $152(16.0)^{\mathrm{a}}$ & $136(14.7)^{\mathrm{a}}$ & $135(15.5)^{\mathrm{a}}$ & \\
\hline Post-high school & & & & & & $\chi^{2}(20)=161.7 * *$ \\
\hline None & $751(64.5)^{\mathrm{a}}$ & $657(57.6)^{\mathrm{b}}$ & $460(48.3)^{\mathrm{c}}$ & $409(43.9)^{\mathrm{c}}$ & $408(46.7)^{\mathrm{c}}$ & \\
\hline Vocational/technical & $331(28.4)^{\mathrm{a}}$ & $380(33.3)^{\mathrm{a}, \mathrm{b}}$ & $352(37.0)^{\mathrm{b}, \mathrm{c}}$ & $390(41.8)^{\mathrm{c}}$ & $313(35.8)^{b, c}$ & \\
\hline Associate & $53(4.5)^{\mathrm{a}}$ & $69(6.0)^{\mathrm{a}, \mathrm{b}}$ & $93(9.8)^{\mathrm{c}}$ & $81(8.7)^{b, c}$ & $83(9.5)^{c}$ & \\
\hline Bachelor's & $20(1.7)^{\mathrm{a}}$ & $25(2.2)^{\mathrm{a}}$ & $33(3.5)^{\mathrm{a}, \mathrm{b}}$ & $34(3.6)^{\mathrm{a}, \mathrm{b}}$ & $52(5.9)^{\mathrm{b}}$ & \\
\hline Master's & $7(.6)^{\mathrm{a}}$ & $10(.9)^{\mathrm{a}}$ & $11(1.2)^{\mathrm{a}}$ & $15(1.6)^{\mathrm{a}}$ & $15(1.7)^{\mathrm{a}}$ & \\
\hline Doctoral & $3(.3)^{\mathrm{a}}$ & $0(.0)^{\mathrm{a}}$ & $3(.3)^{\mathrm{a}}$ & $3(.3)^{\mathrm{a}}$ & $3(.3)^{\mathrm{a}}$ & \\
\hline Current employment & & & & & & $\chi^{2}(24)=869.6^{* *}$ \\
\hline Regular full-time & $232(19.9)^{\mathrm{a}}$ & $316(27.6)^{b}$ & $409(42.9)^{\mathrm{c}}$ & $402(43.1)^{\mathrm{c}}$ & $392(44.7)^{\mathrm{c}}$ & \\
\hline Regular part-time & $157(13.4)^{\mathrm{a}}$ & $138(12.1)^{\mathrm{a}}$ & $104(10.9)^{\mathrm{a}}$ & $111(11.9)^{\mathrm{a}}$ & $91(10.4)^{\mathrm{a}}$ & \\
\hline When available & $203(17.4)^{\mathrm{a}}$ & $42(3.7)^{\mathrm{b}}$ & $23(2.4)^{\mathrm{b}}$ & $24(2.6)^{\mathrm{b}}$ & $19(2.2)^{\mathrm{b}}$ & \\
\hline Looking for work & $14(1.2)^{\mathrm{a}}$ & $152(13.3)^{\mathrm{b}}$ & $102(10.7)^{b, c}$ & $103(11.0)^{b, c}$ & $73(8.3)^{\mathrm{c}}$ & \\
\hline Doesn't work & $562(48.1)^{\mathrm{a}}$ & $430(37.6)^{b}$ & $315(33.1)^{b, c}$ & $293(31.4)^{c}$ & $301(34.4)^{b, c}$ & \\
\hline Currently a student & $0(.0)^{\mathrm{a}}$ & $43(3.8)^{\mathrm{b}}$ & $0(.0)^{\mathrm{a}}$ & $0(.0)^{\mathrm{a}}$ & $0(.0)^{\mathrm{a}}$ & \\
\hline Other & $0(.0)^{\mathrm{a}}$ & $24(2.1)^{\mathrm{a}}$ & $0(.0)^{\mathrm{a}}$ & $0(.0)^{\mathrm{a}}$ & $0(.0)^{\mathrm{a}}$ & \\
\hline Income per year & & & & & & $\chi^{2}(44)=588.4 * *$ \\
\hline$<\$ 5,000$ & $141(12.3)^{\mathrm{a}}$ & $141(12.5)^{\mathrm{a}}$ & $47(5.0)^{\mathrm{b}}$ & $36(3.9)^{\mathrm{b}}$ & $36(4.1)^{\mathrm{b}}$ & \\
\hline$\$ 5,000-\$ 9,999$ & $296(25.9)^{\mathrm{a}}$ & $239(21.2)^{\mathrm{a}}$ & $92(9.7)^{\mathrm{b}}$ & $93(10.0)^{\mathrm{b}}$ & $82(9.4)^{\mathrm{b}}$ & \\
\hline$\$ 10,000-\$ 14,999$ & $210(18.4)^{\mathrm{a}}$ & $214(19.0)^{\mathrm{a}}$ & $123(13.0)^{\mathrm{b}}$ & $128(13.8)^{b}$ & $114(13.1)^{b}$ & \\
\hline$\$ 15,000-\$ 19,999$ & $141(12.3)^{\mathrm{a}}$ & $138(12.3)^{\mathrm{a}}$ & $123(13.0)^{\mathrm{a}}$ & $115(12.4)^{\mathrm{a}}$ & $104(11.9)^{\mathrm{a}}$ & \\
\hline$\$ 20,000-\$ 24,999$ & $109(9.5)^{\mathrm{a}}$ & $89(7.9)^{\mathrm{a}}$ & $93(9.8)^{\mathrm{a}}$ & $89(9.6)^{\mathrm{a}}$ & $77(8.8)^{\mathrm{a}}$ & \\
\hline$\$ 25,000-\$ 29,999$ & $70(6.1)^{\mathrm{a}, \mathrm{b}}$ & $64(5.7)^{\mathrm{b}}$ & $88(9.3)^{\mathrm{a}}$ & $87(9.4)^{\mathrm{a}}$ & $76(8.7)^{\mathrm{a}, \mathrm{b}}$ & \\
\hline$\$ 30,000-\$ 34,999$ & $40(3.5)^{\mathrm{a}}$ & $59(5.2)^{\mathrm{a}, \mathrm{b}}$ & $54(5.7)^{\mathrm{a}, \mathrm{b}}$ & $63(6.8)^{\mathrm{b}}$ & $54(6.2)^{\mathrm{b}}$ & \\
\hline$\$ 35,000-\$ 39,999$ & $25(2.2)^{\mathrm{a}}$ & $50(4.4)^{b}$ & $68(7.2)^{\mathrm{b}, \mathrm{c}}$ & $66(7.1)^{\mathrm{b}, \mathrm{c}}$ & $66(7.6)^{c}$ & \\
\hline$\$ 40,000-\$ 44,999$ & $22(1.9)^{\mathrm{a}}$ & $39(3.5)^{\mathrm{a}, \mathrm{b}}$ & $52(5.5)^{\mathrm{b}}$ & $40(4.3)^{\mathrm{b}}$ & $42(4.8)^{\mathrm{b}}$ & \\
\hline$\$ 45,000-\$ 49,999$ & $22(1.9)^{\mathrm{a}}$ & $26(2.3)^{\mathrm{a}}$ & $44(4.7)^{\mathrm{b}}$ & $44(4.7)^{\mathrm{b}}$ & $45(5.2)^{\mathrm{b}}$ & \\
\hline$>\$ 50,000$ & $67(5.9)^{\mathrm{a}}$ & $66(5.9)^{\mathrm{a}}$ & $125(13.2)^{\mathrm{b}}$ & $133\left(14.3^{\mathrm{b}}\right.$ & $151(17.3)^{b}$ & \\
\hline DK/NA & $0(.0)^{\mathrm{a}}$ & $0(.0)^{\mathrm{a}}$ & $36(3.8)^{\mathrm{b}}$ & $36(3.9)^{\mathrm{b}}$ & $26(3.0)^{\mathrm{b}}$ & \\
\hline
\end{tabular}

Missing values: Age: wave 4=3, wave 6=2, wave 16=9; Race=12; Marital status=8; High school=652; Post-high school=16; Employment=5; Income $=64$.

Notes: Superscript letter indicates that a subset of wave categories does not differ significantly from each other at $\mathrm{p}<.05$ in post-hoc comparison. DK=Don't know; NA=Not applicable.

$* \mathrm{p}<.05 ; * * \mathrm{p}<.01$. 
Table 3

Assessment of longitudinal invariance in Brief CES-D versions

\begin{tabular}{|c|c|c|c|c|c|c|c|}
\hline & \multicolumn{7}{|c|}{ Versions } \\
\hline & A & $\mathrm{B}$ & $\mathrm{C}$ & $\mathrm{D}$ & $\mathrm{E}$ & $\mathrm{F}$ & $\mathrm{G}$ \\
\hline \multicolumn{8}{|l|}{ Baseline } \\
\hline$\chi^{2}$ test $(\mathrm{df})$ & $286.178(215)$ & $410.321(215)$ & $1286.920(854)$ & $1447.880(1060)$ & $1500.227(1065)$ & $1502.404(1060)$ & $1695.236(1305)$ \\
\hline$\chi^{2}$ p value & $<.001$ & $<.001$ & $<.001$ & $<.001$ & $<.001$ & $<.001$ & $<.001$ \\
\hline CFI & .987 & .951 & .965 & .968 & .960 & .951 & .969 \\
\hline RMSEA & .027 & .045 & .034 & .028 & .030 & .031 & .026 \\
\hline RMSEA 90\% C.I. & $.018-.035$ & $.038-.051$ & $.030-.037$ & $.025-.032$ & $.027-.034$ & $.027-.034$ & $.022-.029$ \\
\hline \multicolumn{8}{|l|}{ Loading invariance } \\
\hline$\chi^{2}$ test $(\mathrm{df})$ & $296.784(231)$ & $431.605(231)$ & $1326.556(886)$ & 1508.827 (1096) & $1531.686(1101)$ & 1523.315 (1096) & $1763.433(1344)$ \\
\hline$\chi^{2} \mathrm{p}$ value & .002 & $<.001$ & $<.001$ & $<.001$ & $<.001$ & $<.001$ & $<.001$ \\
\hline CFI & .988 & .950 & .964 & .965 & .960 & .952 & .967 \\
\hline RMSEA & .025 & .044 & .033 & .029 & .029 & .030 & .026 \\
\hline RMSEA $90 \%$ C.I. & $.016-.033$ & $.037-.050$ & $.029-.037$ & $.025-.032$ & $.026-.033$ & $.026-.033$ & $.023-.030$ \\
\hline$\chi^{2}$ difference test $(\mathrm{df})$ & $21.751(17)$ & $32.634(16)$ & $61.200(32)$ & $84.510(36)$ & $49.230(36)$ & $45.076(36)$ & $92.846(39)$ \\
\hline$\chi^{2}$ difference test $\mathrm{p}$ value & .195 & .008 & .001 & $<.001$ & .070 & .142 & $<.001$ \\
\hline \multicolumn{8}{|l|}{ Threshold invariance } \\
\hline$\chi^{2}$ test $(\mathrm{df})$ & $360.362(266)$ & $599.984(267)$ & $1482.687(954)$ & $1619.117(1164)$ & $1624.174(1117)$ & $1594.540(1172)$ & $1887.240(1428)$ \\
\hline$\chi^{2}$ p value & $<.001$ & $<.001$ & $<.001$ & $<.001$ & $<.001$ & $<.001$ & $<.001$ \\
\hline CFI & .983 & .916 & .957 & .962 & .959 & .953 & .963 \\
\hline RMSEA & .028 & .052 & .035 & .029 & .029 & .028 & .027 \\
\hline RMSEA 90\% C.I. & $.020-.035$ & $.047-.058$ & $.032-.039$ & $.026-.033$ & $.026-.032$ & $.025-.032$ & $.023-.030$ \\
\hline$\chi^{2}$ difference test $(\mathrm{df})$ & $90.654(36)$ & $234.838(36)$ & $241.391(68)$ & $159.178(68)$ & $135.432(76)$ & $105.018(76)$ & $175.455(84)$ \\
\hline$\chi^{2}$ difference test $\mathrm{p}$ value & $<.001$ & $<.001$ & $<.001$ & $<.001$ & $<.001$ & .015 & $<.001$ \\
\hline \multicolumn{8}{|l|}{ Unique factor invariance } \\
\hline$\chi^{2}$ test $(\mathrm{df})$ & $391.765(283)$ & $653.060(287)$ & $1503.105(981)$ & 1650.507 (1204) & 1708.459 (1217) & $1698.993(1212)$ & $1930.239(1472)$ \\
\hline$\chi^{2} \mathrm{p}$ value & $<.001$ & $<.001$ & $<.001$ & $<.001$ & $<.001$ & $<.001$ & $<.001$ \\
\hline CFI & .981 & .908 & .957 & .963 & .954 & .946 & .964 \\
\hline RMSEA & .029 & .053 & .034 & .029 & .030 & .030 & .026 \\
\hline RMSEA 90\% C.I. & $.022-.036$ & $.048-.058$ & $.031-.038$ & $.025-.032$ & $.027-.033$ & $.027-.033$ & $.023-.029$ \\
\hline$\chi^{2}$ difference test $(\mathrm{df})$ & $36.161(17)$ & $70.605(20)$ & $49.667(27)$ & $70.731(40)$ & $104.473(40)$ & 120.536 & $79.487(44)$ \\
\hline$\chi^{2}$ difference test $\mathrm{p}$ value & .004 & $<.001$ & $<.001$ & .001 & $<.001$ & $<.001$ & $<.001$ \\
\hline
\end{tabular}

Note: $\chi^{2}$ difference test was performed to compare against the previous step.

CFI: Comparative Fit Index; RMSEA: Root Mean Square Error of Approximation; C.I.: Confidence Interval; df: Degrees of Freedom 
Table 4

Difference in the Predicted Probabilities Threshold Invariance versus Loading Invariance for the CES-D short version A (Shrout \& Yager, 1989)

\begin{tabular}{|c|c|c|c|c|c|}
\hline \multirow[t]{3}{*}{ Response } & \multicolumn{5}{|c|}{ Items in each wave } \\
\hline & \multicolumn{5}{|c|}{ Age 4} \\
\hline & 6 & 11 & 14 & 17 & 20 \\
\hline 0 & .037 & -.030 & -.019 & -.015 & -.013 \\
\hline 1 & -.057 & .033 & .097 & -.003 & .030 \\
\hline 2 & .000 & .002 & -.078 & .011 & .037 \\
\hline \multirow[t]{2}{*}{3} & .019 & .000 & .000 & .007 & -.054 \\
\hline & 6 & 11 & $\frac{\text { Age } 6}{14}$ & 17 & 20 \\
\hline 0 & .024 & -.005 & .002 & -.016 & .006 \\
\hline 1 & -.014 & .018 & .085 & .009 & .032 \\
\hline 2 & .010 & .002 & -.074 & .003 & .002 \\
\hline \multirow[t]{3}{*}{3} & -.021 & -.015 & -.012 & .004 & -.040 \\
\hline & & & Age 12 & & \\
\hline & 6 & 11 & 14 & 17 & 20 \\
\hline 0 & -.020 & .012 & -.015 & .010 & .014 \\
\hline 1 & .017 & .000 & .062 & -.010 & .002 \\
\hline 2 & -.005 & -.019 & -.059 & .003 & .040 \\
\hline \multirow{3}{*}{3} & .008 & .007 & .011 & -.002 & -.056 \\
\hline & & & Age 14 & & \\
\hline & 6 & 11 & 14 & 17 & 20 \\
\hline 0 & -.080 & -.046 & -.053 & -.052 & -.057 \\
\hline 1 & .045 & .008 & .079 & .026 & .031 \\
\hline 2 & .007 & .013 & -.023 & .020 & .046 \\
\hline \multirow{3}{*}{3} & .027 & .025 & -.003 & .005 & -.020 \\
\hline & & & Age 16 & & \\
\hline & 6 & 11 & 14 & 17 & 20 \\
\hline 0 & -.022 & .003 & .011 & .012 & .019 \\
\hline 1 & .025 & -.004 & .061 & -.006 & -.017 \\
\hline 2 & .006 & .019 & -.076 & -.022 & .017 \\
\hline 3 & -.008 & -.017 & .004 & .017 & -.019 \\
\hline
\end{tabular}

Note: Bold highlights an absolute discrepancy above .05

Response categories: $0=$ Rarely or none of the time; $1=$ Some or a little of the time; 2 = Occasionally or a moderate amount of time; $3=$ Most or all of the time. 
Table 5

Difference in the Predicted Probabilities Threshold Invariance versus Loading Invariance for the CES-D short version E (Andresen et al., 1994)

\begin{tabular}{|c|c|c|c|c|c|c|c|c|c|c|}
\hline Response & \multicolumn{10}{|c|}{ Items in each wave } \\
\hline & \multicolumn{10}{|c|}{ Age 4} \\
\hline & 1 & 5 & 6 & 7 & 8 & 10 & 11 & 12 & 14 & 20 \\
\hline 0 & -.016 & -.007 & .058 & .039 & .019 & .038 & -.010 & .007 & -.008 & .011 \\
\hline 1 & .015 & .007 & -.056 & -.031 & -.033 & -.045 & .010 & -.011 & .007 & -.013 \\
\hline 2 & -.002 & .003 & .004 & -.023 & .095 & .010 & .008 & .068 & .011 & .004 \\
\hline 3 & .003 & -.003 & -.005 & .015 & -.081 & -.003 & -.009 & -.064 & -.010 & -.003 \\
\hline \multicolumn{11}{|c|}{ Age 6} \\
\hline & 1 & 5 & 6 & 7 & 8 & 10 & 11 & 12 & 14 & 20 \\
\hline 0 & -.033 & .019 & .027 & .036 & -.026 & .000 & .006 & .027 & .004 & 0.01 \\
\hline 1 & .032 & -.018 & -.027 & -.038 & .039 & -.004 & -.006 & -.033 & -.003 & -.014 \\
\hline 2 & -.005 & -.007 & .009 & .033 & .025 & .007 & .006 & .059 & -.010 & .011 \\
\hline 3 & .006 & .006 & -.009 & -.031 & -.038 & -.003 & -.006 & -.053 & .009 & -.007 \\
\hline \multicolumn{11}{|c|}{ Age 12} \\
\hline & 1 & 5 & 6 & 7 & 8 & 10 & 11 & 12 & 14 & 20 \\
\hline 0 & -.005 & .010 & -.026 & -.016 & .031 & -.003 & .002 & -.018 & -.002 & -.007 \\
\hline 1 & .003 & -.010 & .026 & .019 & -.044 & .006 & .002 & .023 & .002 & .006 \\
\hline 2 & .010 & .002 & -.003 & -.022 & -.029 & -.009 & -.026 & -.050 & .000 & .012 \\
\hline 3 & -.008 & -.001 & .002 & .019 & .042 & .006 & .023 & .044 & .000 & -.011 \\
\hline \multicolumn{11}{|c|}{ Age 14} \\
\hline & 1 & 5 & 6 & 7 & 8 & 10 & 11 & 12 & 14 & 20 \\
\hline 0 & -.006 & .008 & -.024 & -.019 & .015 & -.014 & .008 & -.004 & .005 & -.021 \\
\hline 1 & .009 & -.008 & .023 & .014 & -.024 & .019 & -.008 & .006 & -.005 & .028 \\
\hline 2 & .004 & -.001 & -.016 & .009 & -.045 & -.002 & -.011 & -.048 & .008 & -.016 \\
\hline 3 & -.006 & .001 & .016 & -.004 & .054 & -.004 & .011 & .046 & -.008 & .008 \\
\hline \multicolumn{11}{|c|}{ Age 16} \\
\hline & 1 & 5 & 6 & 7 & 8 & 10 & 11 & 12 & 14 & 20 \\
\hline 0 & .055 & -.026 & -.031 & -.026 & -.018 & -.018 & -.006 & -.010 & .000 & .004 \\
\hline 1 & -.056 & .026 & .032 & .028 & .027 & .021 & .006 & .013 & .002 & -.002 \\
\hline 2 & -.008 & .003 & .002 & -.007 & -.071 & -.009 & .015 & -.036 & -.011 & -.016 \\
\hline 3 & .008 & -.003 & -.003 & .005 & .062 & .006 & -.014 & .033 & .009 & .013 \\
\hline
\end{tabular}

Note: Bold highlights an absolute discrepancy above .05

Response categories: $0=$ Rarely or none of the time; $1=$ Some or a little of the time; $2=$ Occasionally or a moderate amount of time; $3=$ Most or all of the time. 
Table 6

Difference in the Predicted Probabilities Threshold Invariance versus Loading Invariance for the CES-D short version F (Cole et al., 2004)

\begin{tabular}{|c|c|c|c|c|c|c|c|c|c|c|}
\hline \multirow[t]{2}{*}{ Response } & \multicolumn{10}{|c|}{ Items in each wave } \\
\hline & \multicolumn{10}{|c|}{ Age 4} \\
\hline & 1 & 3 & 4 & 5 & 7 & 8 & 9 & 10 & 14 & 15 \\
\hline 0 & -.012 & .010 & .001 & .003 & .049 & .013 & -.018 & .038 & -.004 & -.017 \\
\hline 1 & .015 & -.004 & -.003 & .002 & -.034 & -.025 & .021 & -.042 & .008 & .020 \\
\hline 2 & -.005 & -.006 & .030 & -.001 & -.030 & .089 & -.003 & .008 & .006 & -.007 \\
\hline 3 & .002 & .000 & -.027 & -.003 & .015 & -.077 & .000 & -.004 & -.01 & .003 \\
\hline \multicolumn{11}{|c|}{ Age 6} \\
\hline & 1 & 3 & 4 & 5 & 7 & 8 & 9 & 10 & 14 & 15 \\
\hline 0 & -.031 & .019 & .005 & .021 & .040 & -.030 & -.003 & -.007 & .005 & .003 \\
\hline 1 & .033 & -.014 & -.009 & -.012 & -.027 & .048 & .001 & .004 & .004 & -.011 \\
\hline 2 & -.009 & -.004 & .057 & -.025 & .016 & .015 & .002 & .004 & -.020 & .017 \\
\hline 3 & .007 & -.001 & -.053 & .015 & -.028 & -.032 & .000 & .000 & .012 & -.008 \\
\hline \multicolumn{11}{|c|}{ Age 12} \\
\hline & 1 & 3 & 4 & 5 & 7 & 8 & 9 & 10 & 14 & 15 \\
\hline 0 & -.013 & .006 & .000 & .000 & -.027 & .029 & .005 & .002 & -.002 & -.013 \\
\hline 1 & .011 & -.006 & .005 & -.002 & .028 & -.042 & -.005 & .001 & -.001 & .022 \\
\hline 2 & .009 & -.007 & -.035 & .003 & -.014 & -.028 & .003 & -.005 & .011 & -.014 \\
\hline 3 & -.007 & .007 & .031 & -.001 & .013 & .041 & -.003 & .002 & -.008 & .006 \\
\hline \multicolumn{11}{|c|}{ Age 14} \\
\hline & 1 & 3 & 4 & 5 & 7 & 8 & 9 & 10 & 14 & 15 \\
\hline 0 & .004 & -.027 & .002 & .014 & -.014 & .022 & .003 & -.011 & .005 & -.009 \\
\hline 1 & -.009 & .026 & .002 & -.015 & .015 & -.027 & -.005 & .011 & -.007 & .011 \\
\hline 2 & .013 & .008 & -.022 & -.001 & -.001 & -.047 & .002 & .003 & .005 & -.004 \\
\hline 3 & -.008 & -.007 & .019 & .003 & .000 & .053 & -.001 & -.003 & -.002 & .002 \\
\hline \multicolumn{11}{|c|}{ Age 16} \\
\hline & 1 & 3 & 4 & 5 & 7 & 8 & 9 & 10 & 14 & 15 \\
\hline 0 & .082 & -.017 & .013 & .016 & .058 & .012 & -.029 & -.079 & .005 & -.030 \\
\hline 1 & -.158 & -.100 & -.003 & -.113 & -.071 & -.009 & -.062 & -.017 & -0.104 & -.063 \\
\hline 2 & -.021 & -.005 & -.068 & .001 & -.029 & -.101 & -.012 & -.006 & -0.02 & .012 \\
\hline 3 & .096 & .122 & .059 & .096 & .042 & .098 & .102 & .102 & 0.119 & .080 \\
\hline
\end{tabular}

Note: Bold highlights an absolute discrepancy above .05

Response categories: $0=$ Rarely or none of the time; $1=$ Some or a little of the time; $2=$ Occasionally or a moderate amount of time; $3=$ Most or all of the time. 